\section{IT'S THE THOUGHT THAT COUNTS: THE LINK BETWEEN INTENTION TO ADHERE AND SUCCESSFUL FALLS PREVENTION}

${ }^{1}$ Stefanie Mikolaizak, ${ }^{1}$ Stephen Lord, ${ }^{2}$ Anne Tiedemann, ${ }^{3}$ Paul Simpson, ${ }^{4}$ Kirsten Howard, ${ }^{5}$ Gideon Caplan, ${ }^{1,5}$ Jacqueline Close. ${ }^{1}$ Neuroscience Research Australia, Australia; ${ }^{2}$ The George Institute for Global Health, Australia; ${ }^{3}$ Western Sydney University, Australia; ${ }^{4}$ University of South Australia Business School, Australia; ${ }^{5}$ Prince of Wales Clinical School, UNSW, Australia

\subsection{6/injuryprev-2016-042156.503}

Background A quarter of older fallers requiring ambulance care are subsequently not transported to an emergency department (ED) and due to lack of follow-up care are at high risk for future falls and unplanned health care use. High uptake of and adherence to a falls prevention program are required for an intervention program to be effective at a population level.

Methods A randomised controlled trial investigated the effect of a multidisciplinary, individually tailored fall prevention program offered to older non-transported fallers. Participants comprised 221 people aged $\geq 65$ years. The intervention targeted identified fall risk factors by linking participants with existing healthcare services as appropriate and providing proactive assistance. The control group received written fall prevention advice. Intention to adhere to the intervention was assessed with the AFRIS scale at baseline in the intervention group. Adherence to protocol was reassessed after six months and falls and health service use were monitored for 12 months.

Results Baseline intention to adhere scores (AFRIS) were predictive of adherence rates. Significantly more intervention group participants (proactive assistance) adhered to all recommendations, compared to control group participants (written advice). Adherence was independent of any confounding factors. Adherence with proactive assistance resulted in significantly fewer falls and subsequent health service use compared to non-adhering participants and those who received written advice only. No significant benefit or harm was observed by adhering to written advice. Conclusions Assistance to implement fall prevention interventions, when targeted at individuals intending to adhere to the tailored recommendations, offers significant benefit for participants, regardless of their medical history and fall risk factors. Written advice alone was unable to significantly influence primary outcome measures.

\section{Strategies and Policies}

\section{Post Mon 1.11}

\section{INTEGRATION OF EVIDENCE INTO PRACTICE AND POLICY IN STATE HEALTH DEPARTMENTS IN THE UNITED STATES}

Angela Marr. Centres for Disease Control and Prevention, USA

\subsection{6/injuryprev-2016-042156.504}

Background The Centres for Disease Control and Prevention's (CDC) National Centre for Injury Prevention and Control (NCIPC) empowers states to take action to protect residents and put an end to violence and injuries. NCIPC provides critical funding and technical assistance through its Core Violence and Injury Prevention Program (Core VIPP). The program helps strengthen state capacity to collect and use data to better understand local injury environments and challenges, plan injury prevention and control efforts, and carry out and evaluate life-saving interventions. The Core VIPP modestly funds 20 state health departments at $\$ 250,000$ annually. In order to achieve health impact with limited resources, state health departments strategically utilise implementation partners and evidence based strategies.

Methods The Core VIPP promotes the use of the best available evidence through an annual evaluative review process. Proposed state strategies are compared against a collection of evidencebased registries and emerging evidence compiled by subject matter experts. The best available evidence review findings are shared interactively with state practitioners. Technical assistance is provided to support continuous quality improvement and alignment with evidence. The evaluative review was initiated in Year 1 of a 5 -year program and repeated annually.

Results In Year 3 of the program, 72\% of all state strategies were deemed to be based on the best available evidence in the field. This is up from 59\% in Year 1 and moving towards a 5 -year goal of $80 \%$ of all implemented strategies.

Conclusions These findings provide support for continuing the use of the annual state strategy evaluation. Through technical assistance, rapid feedback and continuous quality improvement, the program was able to increase the number of impactful strategies implemented at the state level.

\section{WHY POLITICAL PRIORITY DID NOT EMERGE FOR ROAD SAFETY IN TURKEY: A POLICY ANALYSIS}

${ }^{1}$ Connie Hoe, ${ }^{2}$ Yeşim Üzümcüoğlu, ${ }^{1}$ Adnan A Hyder. ${ }^{1} J o h n s$ Hopkins International Injury Research Unit, Health Systems Program, Department of International Health, Johns Hopkins Bloomberg School of Public Health, Baltimore, Maryland, USA; ${ }^{2}$ Safety Research Unit, Department of Psychology, Middle East Technical University Ankara, Turkey

\subsection{6/injuryprev-2016-042156.505}

Background Political priority pertains to the agenda setting phase of the policy process whereby an issue emerges as one that draws the attention of and triggers action from high-level decision makers. Few studies have investigated why political priority fails to develop or reemerge for certain public health issues in middle-income countries. In Turkey, road traffic injuries are a major cause of mortality and morbidity. Although, the issue has gained attention in recent years, it has, unfortunately, not received political priority.

Methods Using the Multiple Streams Theory, the process and determinants of why road safety did not become a political priority in Turkey in recent years were explored. A mix-methods case study approach was used. Qualitative data were collected using key informant interviews $(\mathrm{N}=27)$ and document review $(\mathrm{N}=91)$ and analysed using deductive and inductive coding. Quantitative data were collected using an online survey $(\mathrm{N}=95)$ and analysed using descriptive statistics and network nominations. All results were triangulated.

Results In recent years, road safety gained attention in Turkey due to the development of the global and problems streams as well as the presence of actors with personal ties to the Prime Minister. Findings, however, showed that the absence of major crises, an insufficiently favourable political environment, and the presence of a fragmented road safety community prevented the issue from reaching political priority in Turkey. Other barriers included the absence of key actors such as policy entrepreneurs who can champion the cause and strong advocacy-oriented NGOs that can place pressure on the government. 
Conclusions Findings from this study can help these actors devise strategies to promote road safety in Turkey or in other similar contexts.

\section{EVALUATION OF THE STATE OF CITIZEN SAFETY IN FINLAND}

Teija Mankkinen. The Finnish National Rescue Association, Finland

\subsection{6/injuryprev-2016-042156.506}

Background The concept of safety has traditionally been limited to physical security. However, in the 2000s the concept has been expanded to cover also the aspects of social, economic and environmental wellbeing (Kekki 2015). The promotion of safety and security in a global world requires more comprehensive and multi-sectoral cooperation, but also broader and more cross-sectoral information on issues preventing or promoting safety.

Methods The presentation reviews the previous research data available on the topic. Also, the presentation summarises the current state of the citizen safety from the perspective of the previous research and discusses the possible gaps concerning the produced data. The review is based on the data consisting of the previous administration-specific security and safety surveys and studies as well as national surveys.

Results A number of surveys are available on the topic, but most of them define the research topic quite narrowly from the perspective of certain administrative bodies. Only a small amount of data is found on citizen's abilities or opportunities to promote their own safety. Hence, there is also a lack of standardised evaluation criteria for (measuring) citizen safety. In addition, the comparability of data is difficult due to differing definitions of the concepts which are used and the limitations concerning different research settings.

Conclusions The future decision-making needs to be supported by diverse, cross-administrative information about citizen safety and the issues related to security and safety in general. Indicators formed to monitor the development of citizen safety are presented as the conclusions of the presentation.

\section{POLISH ROAD SAFETY OBSERVATORY AS A TOOL FOR EFFECTIVE ROAD SAFETY MANAGEMENT AND POLICY DEVELOPMENT}

Maria Dabrowska-Loranc, Dagmara Jankowska-Karpa, Justyna Wacowska-Slezak, Aneta Wnuk. Motor Transport Institute, Poland

\subsection{6/injuryprev-2016-042156.507}

Background In 2014 Motor Transport Institute established Polish Road Safety Observatory POBR according to the recommendations of National Road Safety Programme GAMBIT 2005-2007-2013 and the assumptions of European Projects SafetyNet and Dacota.

Methods The overall objective of POBR is to contribute to a reduction in the number of road accident victims in Poland. To achieve this goal it is important to provide information about risks on Polish roads and disseminate knowledge concerning road safety. The basic tasks of POBR are as follows: disseminating road safety knowledge, data and information collection and sharing, conducting analyses and research, evaluating programs and activities implemented, cooperation with Regional Road Safety Observatories and other institutions.
Results A reliable road accidents database is essential to identify major problems with regard to road safety. It is also a starting point to plan preventive actions and the source of information in the evaluation process. The accuracy of decisions and the improvement of road safety situation largely depend on the scope and quality of gathered data and conducted analyses. POBR provides national data on road accidents, general population, driver population, vehicle fleet, road network, area. International data are obtained from CARE, OECD, IRTAD and EUROSTAT databases. The data and information in POBR are intended for state and local authorities, road managers, experts from various disciplines, local communities, media, general public and international institutions.

Conclusions The main aim of POBR is to contribute to planing and evaluating knowledge and evidence based actions. POBR can serve as road safety management tool and be useful for road safety policy development. POBR system consists of data warehouse and information portal. An important element of the system is an application, which is designed to create thematic and risk maps which allow the identification of dangerous road sections.

\section{HEALTH IMPACT OF SOBRIETY CHECK POINTS IN MEXICO CITY}

Lourdes Gómez-García, Elisa Hidalgo-Solórzano. Center for Health Systems Research, National Institute of Public Health, Mexico

\subsection{6/injuryprev-2016-042156.508}

Background Random breath testing for vehicle drivers is a costeffective and widely recommended intervention to address drinking and driving. Since September 2003, in Mexico City were implemented random sobriety checkpoints. In 2008, Mexico City joined a comprehensive intervention program, the "Iniciativa Mexicana de Seguridad Vial" (IMESEVI), which also targeted drinking and driving. The aim of this study is to assess the impact of the sobriety checkpoints on rates of collisions and injuries.

Methods We conducted a secondary analysis of official databases on mortality rate, hospital discharges rate, and collisions rate. Information was collected in the period from January, 1999 to December, 2014. We performed a time-series analysis to assess the trend. Twelve month seasonality was considered and the implementation of the IMESEVI in the city.

Results We observed different effects in the monthly trend associated with the implementation of sobriety checkpoints in interaction with IMESEVI. A no significant decrease $(p>0.05)$ was observed for mortality rate $(-0.05$ deaths per 100,000 inhabitants) and hospital discharges rate ( -0.02 discharges per 100,000 inhabitants). The monthly trend for crash rate had a no significant increase $(p>0.05)$ : 0.14 crashes per 100,000 inhabitants per month and 0.41 crashes per 100,000 vehicles per month.

Conclusions Drinking and driving law enforcement in Mexico City is strongly implemented and socially accepted. Despite, legal blood alcohol concentration (BAC) is $0.08 \mathrm{~g} / \mathrm{dl}$, above the recommended $0.04 \mathrm{~g} / \mathrm{dl}$. In order to improve drinking and driving legislation, and obtain better results for sobriety checkpoints, legal BAC levels must be adjusted and zero tolerance for novice driver may be included in the legislation. To improve the evaluation of alcohol consumption deterrence interventions, official registries may include alcohol consumption information. 